\title{
STUDI PEMANFAATAN TUMBUHAN OBAT TRADISIONAL OLEH MASYARAKAT SUKU OIRATA PULAU KISAR KECAMATAN PULAU-PULAU TERSELATAN KABUPATEN MALUKU BARAT DAYA
}

\author{
Beatrixs Rupilu', Theopilus Watuguly ${ }^{2}$ \\ ${ }^{1}$ Alumni Program Studi Pendidikan Biologi \\ ${ }^{2}$ Staf Pengajar Program Studi Pendidikan Biologi \\ E-mail: theo_watuguly@unpatti.fkip.co.id
}

\begin{abstract}
Background: Medicinal plants are medicinal plants that can relieve pain, increase endurance and treat various diseases. The Oirata tribe is an indigenous tribe of Kisar Island. The community traditionally uses various types of plants as alternative treatments to cure diseases because they are easier to obtain and there are no side effects.

Methods: This study uses descriptive methods. Data collection techniques by conducting interviews, observation, questionnaires, and collecting and documenting medicinal plants.

Results: Medicinal plants found in the Oirata Tribe of Kisar Island, the Sub district Islands, Southwest Maluku Regency are 31 types of medicinal plants. Plant parts used are roots, bark, leaves, flowers, fruits and seeds. How to process traditional medicinal plants is done by boiling, pounding, chopping, squeezing, pasting, wrapping, heating, and some even eaten directly to swallow the water.

Conclusion: The way to use it for the people of the Oirata tribe is that it is single because they do not use plants mixed with plants or other raw materials only mixed with water.
\end{abstract}

Keywords: Utilization of plants, traditional medicines, Oirata tribe

\begin{abstract}
Abstrak
Latar Belakang: Tumbuhan obat merupakan tumbuhan berkhasiat obat yang dapat menghilangkan rasa sakit, meningkatkan daya tahan tubuh dan mengobati berbagai macam penyakit. Suku Oirata merupakan suku pribumi Pulau Kisar. Masyarakatnya secara tradisional memanfaatkan berbagai jenis tumbuhan sebagai pengobatan alternatif untuk menyembuhkan penyakit karena lebih mudah didapat dan tidak terdapat efek samping.

Metode Penelitian: Penelitian ini menggunakan metode deskriptif. Teknik pengumpulan data dengan melakukan wawancara, observasi, kuisioner, dan mengumpulkan serta mendokumentasi tumbuhan berkhasiat obat.

Hasil: Tumbuhan obat yang terdapat pada Suku Oirata Pulau Kisar Kecamatan Pulau-Pulau Terselatan Kabupaten Maluku Barat Daya yaitu 31 jenis tumbuhan obat. Bagian tumbuhan yang digunakan adalah akar, kulit batang, daun, bunga, buah dan biji. Cara pengolahan tumbuhan obat tradisional dilakukan dengan cara direbus, ditumbuk, dirajang, diperas, ditempelkan, dibalut, dipanaskan, bahkan ada yang dimakan secara langsung untuk menelan airnya.

Kesimpulan: Cara penggunaanya bagi masyarakat Suku Oirata yaitu bersifat tunggal karena mereka tidak menggunakan tumbuhan yang dicampur dengan tumbuhan atau bahan baku lain hanya dicampur dengan air.
\end{abstract}

Kata kunci: Pemanfaatan tumbuhan, obat tradisional, Suku Oirata 


\section{PENDAHULUAN}

Indonesia merupakan salah satu negara megabiodiversity terbesar di dunia yang kaya akan sumber daya hayati (Putra dkk, 2012). Kekayaan alam tumbuhan di negara ini diperkirakan meliputi 30.000 spesies, 940 spesies diantaranya merupakan tumbuhan yang berkhasiat obat (Masyhud, 2010). Tumbuhan obat merupakan tumbuhan berkhasiat obat yang dapat menghilangkan rasa sakit, meningkatkan daya tahan tubuh dan membunuh bibit penyakit (Darsini, 2013).Bagian tanaman obat yang biasanya digunakan berupa akar, kulit batang, kayu, daun, bunga atau bijinya (Adfa, 2005).

Pemanfaatan tumbuhan obat ini telah dikenal secara turun temurun oleh masyarakat Indonesia untuk mengobati berbagai penyakit luar seperti cacar air maupun penyakit dalam seperti kanker. Jenis-jenis tumbuhan obat yang dimanfaatkan antara lain: Alang-alang (Imerata cylindrical L.), Asam jawa (Tamarindus indicus), Jarak (Jatropa curcas), Jahe (Zingiber oficinalis), Jambu biji (Psidium guajava L), Kumis kucing (Orthosiphon stamineus benth), Pepaya (Carica papaya L) dan sebagainya (Ngarbingan, 2009).

Tradisi pengobatan dan pemanfaatan berbagai jenis tumbuhan obat oleh suatu masyarakat merupakam potensi yang harus tetap dijaga kelestariannya, selain faktor murah, pengaruh sampingan yang rendah juga sesuai dengan kondisi sosial ekonomi dan budaya masyarakat tetapi seiring dengan perkembangan zaman, masyarakat pada umumnya sudah mulai menggunakan obat kimia atau obat-obat dari sarana dan prasarana kesehatan, dikhawatirkan penggunaan obat secara tradisional akan semakin berkurang bahkan hilang, begitu pula dengan populasi dan keberadaan jenis tumbuhan obat akan ikut terancam karena tidak lagi dimanfaatkan dan dipelihara. Namun masih terdapat masyarakat yang menggunakan tumbuhan obat untuk mengobati penyakit yaitu masyarakat Suku Oirata.

Suku Oirata merupakan suku pribumi pulau kisar, suku ini terbagi atas dua desa yaitu Oirata timur dan Oirata barat. Suku Oirata sebagian besar wilayahnya merupakan lahan pertanian. Masyarakat suku oirata merupakan ,masyarakat yang majemuk, sebagian besar penduduknya adalah petani serta berlatar pendidikan yang berbeda-beda mulai dari tingkat kelulusan SD sampai pengguruan tinggi.

Berdasarkan hasil pengamatan sementara, masyarakat suku Oirata sebagian besar memiliki pemahaman tentang pemanfaatan tumbuhan obat tradisional untuk mengobati berbagai jenis penyakit yang diderita. Bahkan ada sebagian masyarakat yang secara khusus dapat dikategorikan sebagai ahli tumbuhan obat tradisional, karena mereka secara praktis dapat mengobati orang lain dengan tumbuhan obat tradisional. Atas dasar ini penelitian ini penting diteliti agar dapat memberikan informasi kepada masyarakat maupun pemerintahan bahwa terdapat jenis-jenis tumbuhan obat di Suku Oirata yang dapat digunakan sebagai obat tradisional.

\section{MATERI DAN METODE}

Tipe penelitian yang digunakan adalah deskriptif untuk mengetahui jenis tumbuhan obat yang dipakai sebagai obat tradisional, mengetahuai jenis penyakit yang bisa diobati dengan menggunakan tumbuhan obat, mengetahui bagian tumbuhan obat yang digunakan untuk menyembuhkan penyakit, mengetahui bagaimana cara pengelolahan dan pemanfaatan tumbuhan obat oleh masyarakat Suku Oirata Pulau Kisar Kecamatan Pulau-Pulau Terselatan Kabupaten Maluku Barat Daya.

Penelitian ini dilaksanakan di Suku Oirata Pulau Kisar Kecamatan Pulau-Pulau Terselatan Kabupaten Maluku Barat Daya. Populasi dalam penelitian ini adalah seluruh jenis tanaman obat yang tersebar serta masyarakat Suku Oirata Pulau Kisar Kecamatan Pulau-Pulau Terselatan Kabupaten Maluku Barat Daya. Teknik pengumpulan data ini adalah 1) Kepustakaan: studi pustaka digunakan untuk mencari informasi tentang tumbuhan obat dan bentuk pemanfaatannya dari literatur seperti skripsi, tesis, disertasi, maupun jurnal ilmiah untuk digunakan sebagai acuan dan referensi dalam melengkapi data yang diperoleh dan 2). 
Data Lapangan (Data Primer)

Data primer yaitu data yang diperoleh pada saat mengadakan penelitian dengan menggunakan teknik observasi, wawancara, dan kuisioner yang ditunjukan kepada masyarakat dengan penentuan responden sebagai berikut:

a. Pengobat Tradisional sebanyak 5 orang pemuka adat diwawancara pada

b. Masing-masing desa yang terdiri atas 5 orang.

c. Berdasarkan strata umur yaitu dari 18 tahun ke atas

d. Berdasarkan strata pendidikan dari tingkat SD sampai perguruan tinggi

e. Berdasarkan strata pekerjaan dari petani sampai PNS
Setelah melakukan observasi, wawancara, dan kuisioner maka akan dilakukan dokumentasi spesies tumbuhan yang telah didapat dan pengambilan titik tumbuhan obat guna untuk diidentifikasi serta dibuat herbarium.

\section{HASIL DAN PEMABAHASAN}

Berdasarkan hasil pengamatan, wawancara dan survey yang dilakukan, maka jenis tumbuhan obat yang digunakan untuk menyembuhkan penyakit yang ditemukan dapat dilihat pada tabel 1 berikut.

Tabel 1. Jenis Tumbuhan Obat yang Digunakan untuk Menyembuhkan Penyakit

\begin{tabular}{|c|c|c|c|c|}
\hline No & Nama Umum & Nama IImiah & Nama Lokal & Habitus \\
\hline 1 & Jarak pagar & Jatropa curcas L. & Jarak putih & Perdu \\
\hline 2 & Canar & Smilax leucophylla & Wando & Merambat \\
\hline 3 & Jambu monyet & Anacardium occidentale L & Jambu mete & Pohon \\
\hline 4 & Srikaya & Annona squamosa $\mathrm{L}$. & Srikaya & Pohon \\
\hline 5 & Pepaya & Carica papaya L. & Pepaya & Pohon \\
\hline 6 & Tapak dara & Catharanthus roseus & Bunga pica piring & Semak \\
\hline 7 & Alang-alang & Imperata cylindrica & Kusus-kusu & Herba \\
\hline 8 & Kelor & Moringa oleifera Lam & Kelor & Pohon \\
\hline 9 & Lidah buaya & Aloe vera $\mathrm{L}$. & Lidah buaya & Herba \\
\hline 10 & Jambu biji & Psidium guajava L. & Guyawas & Perdu \\
\hline 11 & Mengkudu & Morinda citrifolia L. & Mengkudu & Pohon \\
\hline 12 & Sirsak & Annona muricata L. & Sirsak & Pohon \\
\hline 13 & Asam Jawa & Tamarindus indica $\mathrm{L}$. & Asam jawa & Pohon \\
\hline 14 & Jeruk Nipis & Citrus $x$ aurantiifolia & Lemon nipis & Perdu \\
\hline 15 & Kemangi & Ocimum citriodorum & Tarutuk & Herba \\
\hline 16 & Tembelekan & Lantana camara L. & Amankoi & Perdu \\
\hline 17 & Sirih & Piper betle & Sirih & Merambat \\
\hline 18 & Turi & Sesbania grandiflora & Turi & Pohon \\
\hline 19 & Jarak merah & Jatropha gossypifolia L. & Jarak merah & Semak \\
\hline 20 & Kirinyu & Chromolaena odorata L. & Sungga-sungga & Perdu \\
\hline 21 & Sirih hutan & Piper caducibrateum C.DC & Sirih hutan & Semak \\
\hline 22 & Kamboja Putih & Plumeria alba & Kamboja putih & Pohon \\
\hline 23 & Sukun & Artocarpus altilis & Sukun & Pohon \\
\hline 24 & Cabai & Capsicum annun L. & Cili & Perdu \\
\hline 25 & Kecubung & Datura mete/ L. & Kecubung & Perdu \\
\hline 26 & Suruhan & Peperomia pellucida & Nona muka manis & Herba \\
\hline 27 & Pisang Raja & Musa $x$ paradisiaca $\mathrm{AAB}$ & Pisang raja & Herba \\
\hline 28 & Daun afrika & Vernonia amygdalina Del. & Daun afrika & Semak \\
\hline 29 & Belimbing wuluh & Averrhoa bilimbi $\mathrm{L}$. & Belimbing asam & Pohon \\
\hline 30 & Pare & Momordica charantia L. & Papari & Merambat \\
\hline 31 & Nangka & $\begin{array}{l}\text { Artocarpus heterophyllus } \\
\text { Lamk. }\end{array}$ & Nangka & Pohon \\
\hline
\end{tabular}


Biopendix, Volume 5, Nomor 1, Oktober 2018, hlm. 53-64

Tabel 2. Bagian Tanaman Obat Yang Digunakan Untuk Meyembuhkan Penyakit

\begin{tabular}{|c|c|c|}
\hline No & Nama Tanaman & Bagian Tanaman yang digunakan \\
\hline 1 & Jarak Pagar (Jatropa curcas L.) & $\begin{array}{l}\text { Bagian tanaman yang digunakan yaitu bagian pucuk } \\
\text { daun dan getah. Pucuk daunnya untuk menurunkan } \\
\text { demam dan getah untuk mencuci lidah yang putih pada } \\
\text { bayi }\end{array}$ \\
\hline 2 & Canar (Smilax leucophylla) & $\begin{array}{l}\text { Bagian tanaman yang digunakan yaitu daun untuk } \\
\text { menarik darah mati pada luka }\end{array}$ \\
\hline 3 & $\begin{array}{l}\text { Jambu monyet (Anacardium } \\
\text { occidentale L.) }\end{array}$ & $\begin{array}{l}\text { Bagian tanaman yang digunakan yaitu pucuk daun } \\
\text { untuk menyembuhkan penyakit diare }\end{array}$ \\
\hline 4 & Srikaya (Annona squamosa L.) & $\begin{array}{l}\text { Bagian tanaman yang digunakan yaitu daun dan biji. } \\
\text { Daunnya untuk perut kembung dan bijinya untuk } \\
\text { bengkak saat digigit nyamuk. }\end{array}$ \\
\hline 5 & Pepaya (Carica papaya L.) & $\begin{array}{l}\text { Bagian tanaman yang digunakan yaitu pucuk daun, biji, } \\
\text { buah,akar. Pucuk daunnya untuk menyembuhkan } \\
\text { penyakit malaria, biji untuk cacingan, buah untuk susah } \\
\text { BAB dan akarnya untuk menyembuhkan penyakit } \\
\text { darah tinggi. }\end{array}$ \\
\hline 6 & Tapak Dara (Catha ranthusroseus) & $\begin{array}{l}\text { Bagian tanaman yang digunakan yaitu batang, daun, } \\
\text { dan bunga. Untuk menyembuhkan penyakit darah } \\
\text { tinggi. }\end{array}$ \\
\hline 7 & Alang-alang (Imperata cylindrical) & $\begin{array}{l}\text { Bagian tanaman yang digunakan yaitu akar. Untuk } \\
\text { mengurangi kerontokan rambut, meyembuhkan } \\
\text { penyakit diare dam rematik. }\end{array}$ \\
\hline 8 & Kelor (Moringa oleifera Lam) & $\begin{array}{l}\text { Bagian tanaman yang digunakan yaitu daun. Untuk } \\
\text { menyembuhkan sakit mata. }\end{array}$ \\
\hline 9 & Lidah Buaya (Aloe vera L.) & $\begin{array}{l}\text { Bagian tanaman yang digunakan yaitu daun (gel). } \\
\text { Untuk menyembuhkan luka bakar, meyuburkan rambut, } \\
\text { dan menghilangkan jerawat. }\end{array}$ \\
\hline 10 & Jambu Biji (Psidium guajava L.) & $\begin{array}{l}\text { Bagian tanaman yang digunakan yaitu pucuk daun. } \\
\text { Untuk menyembuhkan gusi yang bengkak dan diare }\end{array}$ \\
\hline & Mengkudu (Morinda citrifolia L.) & $\begin{array}{l}\text { Bagian tanaman yang digunakan yaitu daun. Daunnya } \\
\text { untuk menyembuhkan badan yang sakit (radang } \\
\text { persendian) sedangakan buah untuk menyembuhkan } \\
\text { penyakit darah tinggi. }\end{array}$ \\
\hline 12 & Sirsak (Annona muricata L.) & $\begin{array}{l}\text { Bagian tanaman yang digunakan yaitu daun. Untuk } \\
\text { menyembuhkan penyakit darah tinggi. }\end{array}$ \\
\hline 13 & Asam Jawa (Tamarindus indica L.) & $\begin{array}{l}\text { Bagian tanaman yang digunakan yaitu daun dan kulit. } \\
\text { Daunnya untuk menyembuhkan cacar air dan kulitnya } \\
\text { untuk meyembuhkan penyakit asma }\end{array}$ \\
\hline 14 & Jeruk Nipis (Citrus $x$ aurantiifolia) & $\begin{array}{l}\text { Bagian tanaman yang digunakan yaitu buah. Untuk } \\
\text { menyembuhkan sakit tenggorokan }\end{array}$ \\
\hline 15 & Kemangi (Ocimum citriodorum) & $\begin{array}{l}\text { Bagian tanaman yang digunakan adalah daun. Daunya } \\
\text { untuk menghilangkan bauh badan. }\end{array}$ \\
\hline 16 & Tembelekan (Lantana camara L.) & $\begin{array}{l}\text { Bagian tanaman yang digunakan adalah daun dan } \\
\text { kembang. Untuk menyembuhkan penyakit batuk. }\end{array}$ \\
\hline 17 & Sirih (Piper betle) & $\begin{array}{l}\text { Bagian tanaman yang digunakan adalah daun. } \\
\text { Daunnya digunakan untuk menghilangkan keputihan } \\
\text { dan memperlancar HAID }\end{array}$ \\
\hline 18 & Turi (Sesbania grandiflora) & $\begin{array}{l}\text { Bagian tanaman yang kulit batang bagian dalam. Kulit } \\
\text { batang bagian dalamya untuk meyembuhkan penyakit } \\
\text { darah putih bagi ibu yang selesai melahirkan }\end{array}$ \\
\hline 19 & $\begin{array}{l}\text { Jarak merah (Jatropha gossypifolia } \\
\text { L.) }\end{array}$ & $\begin{array}{l}\text { Bagian tanaman yang digunakan adalah daun. } \\
\text { Daunnya untuk meyembuhkan penyakit kanker } \\
\text { payudara. }\end{array}$ \\
\hline 20 & Kirinyu (Chromolaena odorata L.) & $\begin{array}{l}\text { Bagian tanaman yang digunakan adalah daun. } \\
\text { Daunnya untuk meyembuhkan luka goresan yang } \\
\text { berdarah. }\end{array}$ \\
\hline
\end{tabular}




\begin{tabular}{lll}
\hline 21 & $\begin{array}{l}\text { Sirih hutan (Piper caducibrateum } \\
\text { C.DC) }\end{array}$ & $\begin{array}{l}\text { Bagian tanaman yang digunakan adalah akar. Akarnya } \\
\text { untuk meyembuhkan patah tulang. }\end{array}$ \\
\hline 22 & Kamboja putih (Plumeria alba) & $\begin{array}{l}\text { Bagian tanaman yang digunakan adalah kulit batang. } \\
\text { Kulit batangnya untuk menyembuhkan penyakit demam } \\
\text { berdarah }\end{array}$ \\
\hline 23 & Sukun (Artocarpus altilis) & $\begin{array}{l}\text { Bagian tanaman yang digunakan adalah daun yang } \\
\text { telah kuning. Untuk menyembuhknnya penyakit kuning. }\end{array}$ \\
\hline 24 & Cabai (Capsicum annun L.) & $\begin{array}{l}\text { Bagian tanaman yang digunakan adalah daun. } \\
\text { Daunnya untuk menyembuhkan bisul }\end{array}$ \\
\hline 25 & Kecubung (Datura metel L.) & $\begin{array}{l}\text { Bagian tanaman yang digunakan adalah daun dan } \\
\text { buahnya. Daunnya untuk penurun panas dan buahnya } \\
\text { untuk sakit telinga. }\end{array}$ \\
\hline 26 & Suruhan (Peperomia pellucida) & $\begin{array}{l}\text { Bagian tanaman yang digunakan adalah batang dan } \\
\text { daunnya. Batang dan daunnya untuk menyembuhkan } \\
\text { penyakit asam urat. }\end{array}$ \\
& & $\begin{array}{l}\text { Bagian tanaman yang digunakan adalah buah. } \\
\text { Buahnya untuk menyembuhkan penyakit gula darah. }\end{array}$ \\
\hline 27 & Pisang raja (Musa X paradisiaca \\
AAB) & $\begin{array}{l}\text { Bagian tanaman yang digunakan adalah daun. } \\
\text { Daunnya untuk meyembuhkan penyakit gagal ginjal. }\end{array}$ \\
\hline 28 & Daun afrika (Vernonia amygdalina \\
Del) & Belimbing wuluh (Averrhoa bilimbi L) & $\begin{array}{l}\text { Bagian tanaman yang digunakan adalah buah. } \\
\text { Buahnya untuk meyembuhkan penyakit gondok. }\end{array}$ \\
\hline 29 & $\begin{array}{l}\text { Bagian tanaman yang digunakan adalah akar, daun, } \\
\text { buah dan bijinya. Untuk meyembuhkan penyakit } \\
\text { ambeyen. }\end{array}$ \\
\hline 30 & Pare (Momordica charantia L) & $\begin{array}{l}\text { Bagian tanaman yang digunakan adalah getah. } \\
\text { Getahnya untuk meyembuhkan bisul. }\end{array}$ \\
& & Nangka (Artocarpus heterophyllus \\
\hline 31 & Lamk)
\end{tabular}

Tabel 3. Jenis Penyakit Yang Disembuhkan Menggunakan Tanaman Obat Tradisional dan Cara Pengolahannya.

\begin{tabular}{|c|c|c|c|}
\hline No & Nama Tanaman & Jenis Penyakit & $\begin{array}{c}\text { Cara Pengolahan } \\
\end{array}$ \\
\hline 1 & $\begin{array}{l}\text { Jarak Pagar (Jatropa } \\
\text { curcas L.) }\end{array}$ & $\begin{array}{l}\text { Demam dan lidah } \\
\text { putih pada bayi }\end{array}$ & $\begin{array}{l}\checkmark \text { Demam } \\
\text { Ambil } 3 \text { pucuk daun jarak diolesi minyak } \\
\text { kelapa dan ditempelkan diatas perut diikat } \\
\text { mengunakan kain agar daun jaraknya tidak } \\
\text { jatuh atau terlepas dari perut diamkan } \\
\text { sampai daun jaraknya menjadi layu } \\
\text { diangkat dan diganti dengan daun jarak } \\
\text { baru. Lakukan berulang kali sampai } \\
\text { demamnya menjadi turun. } \\
\checkmark \text { Lidah putih pada bayi } \\
\text { Ambil getah jarak yang terdapat pada } \\
\text { daunnya oleskan pada lidah yang putih } \\
\text { sampai bersih }\end{array}$ \\
\hline 2 & $\begin{array}{l}\text { Canar (Smilax } \\
\text { leucophylla) }\end{array}$ & $\begin{array}{l}\text { Darah mati pada } \\
\text { luka }\end{array}$ & $\begin{array}{l}\text { Ambil daun canar secukupnya di tumbuk } \\
\text { sampai halus dan berair, kemudian } \\
\text { ditempelkan pada kaki yang bengkak akibat } \\
\text { keseleo atau patah dan ikat menggunakan } \\
\text { kain agar daun canar tersebut tidak jatuh } \\
\text { biarkan hingga tumbukan daun tersebut } \\
\text { menjadi kering. Lakukan berulang kali agar } \\
\text { bengkaknya berkurang akibat darah matiya } \\
\text { ditarik. }\end{array}$ \\
\hline 3 & $\begin{array}{l}\text { Jambu monyet } \\
\text { (Anacardium occidentale } \\
\text { L.) }\end{array}$ & Diare & $\begin{array}{l}\text { Ambil beberapa pucuk daun jambu biji, } \\
\text { kemudian dikunyah telan airnya agar dapat } \\
\text { membantu menyembuhkan sakit perut dan } \\
\text { diare }\end{array}$ \\
\hline 4 & $\begin{array}{l}\text { Srikaya (Annona } \\
\text { squamosa L.) }\end{array}$ & $\begin{array}{l}\text { Perut kembung dan } \\
\text { gigitan nyamuk }\end{array}$ & $\begin{array}{l}\checkmark \quad \text { Perut kembung } \\
\text { Ambil } 5 \text { daun srikaya, kemudian panaskan }\end{array}$ \\
\hline
\end{tabular}




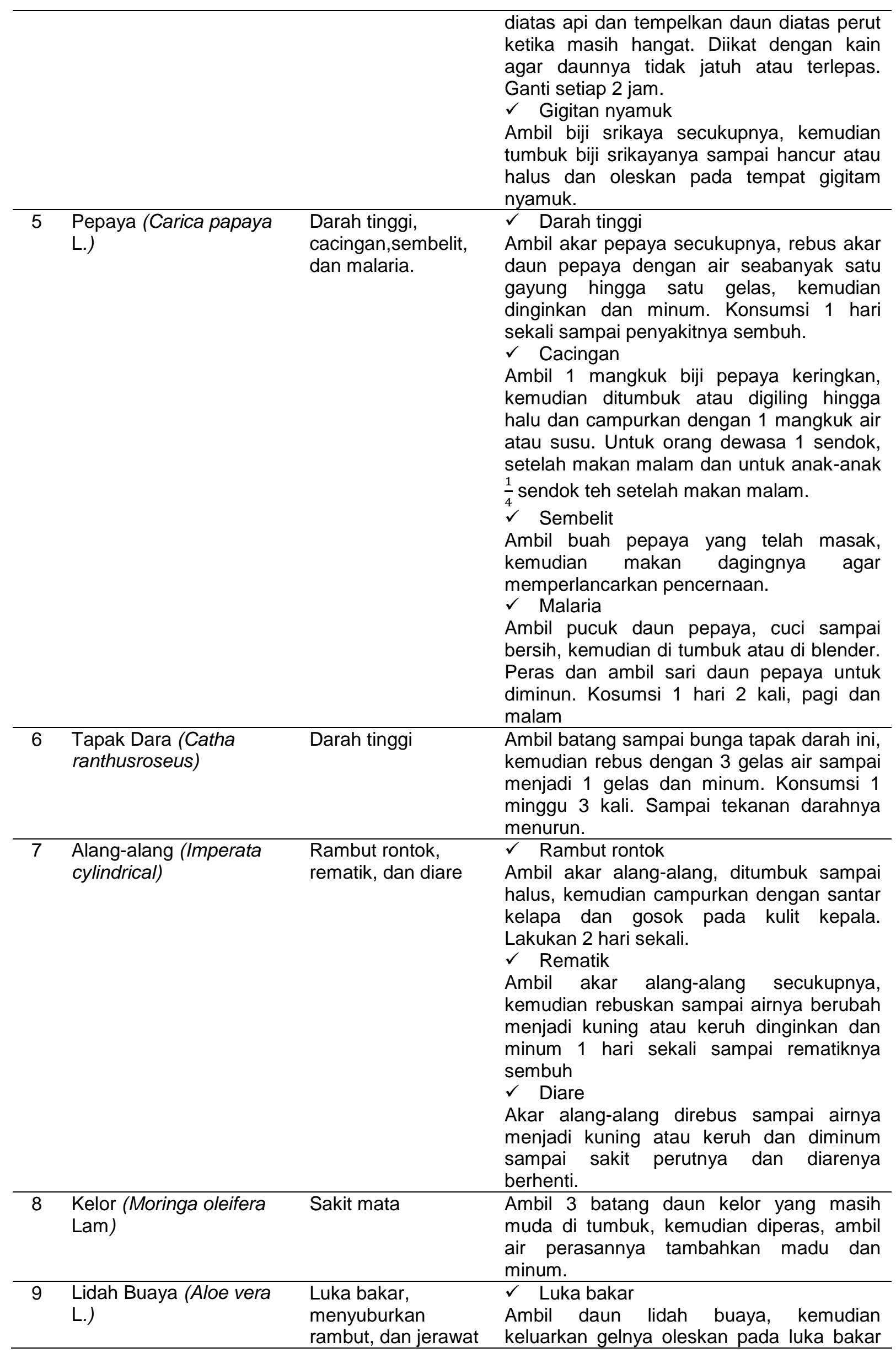




\begin{tabular}{|c|c|c|c|}
\hline & & & $\begin{array}{l}\text { sampai sakitnya berhenti dan empuknya } \\
\text { berkurang. } \\
\checkmark \text { Menyuburkan rambut } \\
\text { Ambil daun lidah buaya, kemudian } \\
\text { keluarkan gelnya dan oleskan pada kulit } \\
\text { kepala hingga seluruh kepala atau } \\
\text { rambutnya berair diamkan selama } 1 \text { jam } \\
\text { dan cuci sampai bersih. Lakukan } 3 \text { kali } \\
\text { dalam } 1 \text { minnggu. } \\
\checkmark \text { Jerawat } \\
\text { Oleskan gel lidah buah pada wajah yang } \\
\text { terdapat jerawat. Lakukan } 1 \text { hari sekali } \\
\text { sampai jerawatnya hilang atau sembuh. }\end{array}$ \\
\hline 10 & $\begin{array}{l}\text { Jambu Biji (Psidium } \\
\text { guajava L.) }\end{array}$ & $\begin{array}{l}\text { Diare dan gusi } \\
\text { bengkak }\end{array}$ & $\begin{array}{l}\checkmark \\
\text { Ambil } 10 \text { pucuk daun jambu biji, kemudian } \\
\text { dirajang dalam gelas air selama } 15 \text { menit. } \\
\text { Untuk orang dewasa } 1 \text { gelas, } 3 \text { kali sehari, } \\
\text { setiap kali selesai BAB dan untuk anak- } \\
\text { anak } 1 \text { sendok makan, } 3 \text { kali sehari, setiap } \\
\text { kali selesai BAB. } \\
\checkmark \quad \text { Gusi bengkak } \\
\text { Ambil daun jambu biji secukupnya, } \\
\text { kemudian rajang tambahkan air } 2 \text { gelas, } \\
\text { rebus selama } 10 \text { menit. Saring dan } \\
\text { dinginkan. Tambahkan gara secukupnya } \\
\text { kedalam air rebusan untuk berkumur } \\
\text { setelah selesai makan. }\end{array}$ \\
\hline 11 & $\begin{array}{l}\text { Mengkudu (Morinda } \\
\text { citrifolia L.) }\end{array}$ & Nyeri persendian & $\begin{array}{l}\text { Ambil daun mengkudu secukupnya, } \\
\text { kemudian rebus hingga airnya berubah } \\
\text { menjadi kuning atau keruh dan diamkan } \\
\text { hingga hangat untuk dijadikan air mandi. }\end{array}$ \\
\hline 12 & $\begin{array}{l}\text { Sirsak (Annona muricata } \\
\text { L.) }\end{array}$ & Darah tinggi & $\begin{array}{l}\text { Ambil } 5 \text { daun sirsak, kemudian cuci dan } \\
\text { rebus dengan air sebanyak } 3 \text { gelas hingga } \\
\text { menjadi satu gelas. Diamkan hingga } \\
\text { menjadi hangat. Konsumsi } 2 \text { hari sekali } \\
\text { sampai tekanan darahnya turun atau } \\
\text { menjadi normal. }\end{array}$ \\
\hline 13 & $\begin{array}{l}\text { Asam Jawa (Tamarindus } \\
\text { indica L.) }\end{array}$ & Asma dan cacar air & $\begin{array}{l}\checkmark \text { Asma } \\
\text { Ambil kulit batang asam jawa secukupnya, } \\
\text { kemudian rajang dan rebus dengan air } \\
\text { sebanyak } 3 \text { gelas selama } 10 \text { menit. } \\
\text { Konsumsi } 3 \text { kali hari sekali setelah makan } \\
\text { dan sebelum tidur. } \\
\checkmark \quad \text { Cacar air } \\
\text { Ambil daun asam jawa secukupnya, } \\
\text { kemudian rebus sampai air berubah } \\
\text { menjadi kuning atau keruh. Hnagatkan air } \\
\text { rebusan tersebut dan digunakan sebagai air } \\
\text { mandi. }\end{array}$ \\
\hline 14 & $\begin{array}{l}\text { Jeruk Nipis (Citrus } x \\
\text { aurantiifolia) }\end{array}$ & $\begin{array}{l}\text { Radang } \\
\text { tenggorokan }\end{array}$ & $\begin{array}{l}\text { Ambil } 1 \text { buah jeruk nipis, kemudian peras } \\
\text { tambahkan air } 1 \text { gelas dan campurkan } \\
\text { madu atau kecap. Konsumsi } 1 \text { hari sekali } \\
\text { sampai radang tenggorokannya sembuh. }\end{array}$ \\
\hline 15 & $\begin{array}{l}\text { Kemangi (Ocimum } \\
\text { citriodorum) }\end{array}$ & $\begin{array}{l}\text { Menghilangkan bau } \\
\text { badan }\end{array}$ & $\begin{array}{l}\text { Ambil daun kumangi secukupnya, dicuci } \\
\text { hingga bersih kemudian langsung dimakan } \\
\text { mentah atau di tumbuk hingga hancur untuk } \\
\text { diambilkan airnya dan minum. }\end{array}$ \\
\hline 16 & $\begin{array}{l}\text { Tembelekan (Lantana } \\
\text { camara L.) }\end{array}$ & Batuk & $\begin{array}{l}\text { Ambil } 1 \text { mangkuk daun serta kembang } \\
\text { segar dan rebuskan selama } 15 \text { menit, } \\
\text { kemudian diamkan hingga menjadi hangat }\end{array}$ \\
\hline
\end{tabular}




\begin{tabular}{|c|c|c|c|}
\hline & & & $\begin{array}{l}\text { dan minum. Dikonsumsi sebanyak } 1 / 2 \\
\text { mangkuk } 3 \text { kali sehari untuk orang dewasa } \\
\text { dan untuk anak-anak } 2 \text { sendok makan } 3 \text { kali } \\
\text { sehari. }\end{array}$ \\
\hline 17 & Sirih (Piper betle) & $\begin{array}{l}\text { Keputihan dan } \\
\text { memperlancar HAID }\end{array}$ & $\begin{array}{l}\checkmark \text { Keputihan } \\
\text { Ambil } 5 \text { lembar daun sirih yang tidak terlalu } \\
\text { muda, cuci dan rebuskan hingga airnya } \\
\text { berubah menjadi kuning atau keruh, } \\
\text { kemudian diamkan hingga hangat dan } \\
\text { gunakana untuk cebok setiap kali buang air } \\
\text { besar atau kecil. } \\
\checkmark \quad \text { Memperlancar HAID } \\
\text { Ambil } 5 \text { lembar daun sirih yang tidak terlalu } \\
\text { muda, cuci dan rebuskan hingga airnya } \\
\text { berubah menjadi kuning atau keruh, } \\
\text { kemudian diamkan hingga hangat dan } \\
\text { minum. Dikonsumsi } 1 \text { Gelas } 1 \text { hari. }\end{array}$ \\
\hline 18 & $\begin{array}{l}\text { Turi (Sesbania } \\
\text { grandiflora) }\end{array}$ & Darah putih & $\begin{array}{l}\text { Ambil bagian dalam kulit batang turih yang } \\
\text { masih segar secukupnya, kemudian tumbuk } \\
\text { hingga hancur dan tempelkan di dahi, } \\
\text { bebatkan atau diikat menggunakan kain } \\
\text { agar tidak mudah jatuh. }\end{array}$ \\
\hline 19 & $\begin{array}{l}\text { Jarak merah (Jatropha } \\
\text { gossypifolia L.) }\end{array}$ & Kanker payudara & $\begin{array}{l}\text { Ambil } 5 \text { daun jarak merah, kemudian rebus } \\
\text { hinga airnya berubah menjadi keruh, } \\
\text { diamkan hingga menjadi hangat dan } \\
\text { minum. Konsumsi } 1 \text { gelas } 3 \text { kali sehari pagi, } \\
\text { siang dan malam. }\end{array}$ \\
\hline 20 & $\begin{array}{l}\text { Kirinyu (Chromolaena } \\
\text { odorata L.) }\end{array}$ & $\begin{array}{l}\text { Luka gores yang } \\
\text { berdarah }\end{array}$ & $\begin{array}{l}\text { Ambil daun kirinyu yang masi mudah } \\
\text { secukupnya, cuci hingga bersih, kemudian } \\
\text { di kucak atau di tumbuk hingga berlendir } \\
\text { dan tempelkan pada luka untuk } \\
\text { menghentikan darahnya. }\end{array}$ \\
\hline 21 & $\begin{array}{l}\text { Sirih hutan (Piper } \\
\text { caducibrateum C.DC) }\end{array}$ & Patah tulang & $\begin{array}{l}\text { Ambil akar sirih hutan yang masih segar } \\
\text { tumbuk hingga menjadi hancur dan } \\
\text { tempelkan pada tulang yang patah. }\end{array}$ \\
\hline 22 & $\begin{array}{l}\text { Kamboja putih (Plumeria } \\
\text { alba) }\end{array}$ & Demam berdarah & $\begin{array}{l}\text { Ambil kulit batang secukupnya, rebuskan } \\
\text { hingga airnya menjadi keruh. Diamkan } \\
\text { hingga menjadi hangat dan minum. } \\
\text { konsusmsi } 1 \text { gelas } 1 \text { hari pada pagi hari. }\end{array}$ \\
\hline 23 & Sukun (Artocarpus altilis) & Penyakit kuning & $\begin{array}{l}\text { Ambil daun sukun kuning, cucih hingga } \\
\text { bersih, kemudian rebuskan hingga air } \\
\text { rebusannya berubah menjadi kuning dan } \\
\text { minum. Dikonsumsi sebagai peganti air } \\
\text { minum ketika merasa haus sampai penyakit } \\
\text { kuningya sembuh. }\end{array}$ \\
\hline 24 & $\begin{array}{l}\text { Cabai (Capsicum annun } \\
\text { L.) }\end{array}$ & Bisul & $\begin{array}{l}\text { Ambil daun cabai yang masih mudah } \\
\text { letakan dia ataa api hingga daunnya } \\
\text { menjadi layu, kemudian oleskan minyak } \\
\text { sedikit pada permukaan daunya dan } \\
\text { tempelkan pada bagian tubuh yang terkena } \\
\text { bisul. }\end{array}$ \\
\hline 25 & $\begin{array}{l}\text { Kecubung (Datura metel } \\
\text { L.) }\end{array}$ & $\begin{array}{l}\text { Penurun panas } \\
\text { (Demam) dan sakit } \\
\text { telinga }\end{array}$ & $\begin{array}{l}\text { Penurun panas ( Demam) } \\
\text { Ambil pucuk daun kecubung diolesi minyak } \\
\text { kelapa dan ditempelkan diatas perut diikat } \\
\text { mengunakan kain agar daun kecubungnya } \\
\text { tidak jatuh atau terlepas dari perut diamkan } \\
\text { sampai daun kecubungnya menjadi layu } \\
\text { diangkat dan diganti dengan daun } \\
\text { kecubung baru. Lakukan berulang kali } \\
\text { sampai demamnya menjadi turun. }\end{array}$ \\
\hline
\end{tabular}




\begin{tabular}{|c|c|c|c|}
\hline & & & $\begin{array}{l}\checkmark \text { Sakit } \\
\text { Ambil buah kecubung bagian pangkalnya } \\
\text { dipotong dan teteskan beberapa tetes } \\
\text { minyak kelapa, kemudian letakan di atas api } \\
\text { untuk memanaskan kemudian tetes didalam } \\
\text { telinga selagi masih hangat. }\end{array}$ \\
\hline 26 & $\begin{array}{l}\text { Suruhan (Peperomia } \\
\text { pellucida) }\end{array}$ & Asam Urat & $\begin{array}{l}\text { Ambil daun dan batang suruhan, cuci } \\
\text { dengan air hangat, kemudian kunya daun } \\
\text { beserta batang dan telan sarinya. }\end{array}$ \\
\hline 27 & $\begin{array}{l}\text { Pisang raja (Musa } X \\
\text { paradisiaca } A A B)\end{array}$ & $\begin{array}{l}\text { Gula darah } \\
\text { (Diabetes) }\end{array}$ & $\begin{array}{l}\text { Ambil buah pisang raja yang masih mentah } \\
\text { kupas dan rebus isinya hingga menjadi } \\
\text { matang, kemudian makan sebagai } \\
\text { pengganti nasi. }\end{array}$ \\
\hline 28 & $\begin{array}{l}\text { Daun afrika (Vernonia } \\
\text { amygdalina Del) }\end{array}$ & Gagal ginjal & $\begin{array}{l}\text { Ambil daun Afrika secukupnya, cuci hingga } \\
\text { bersih, kemudian rebus selama } 15 \text { menit. } \\
\text { Hangatkan dan minum. Konsumsi } 1 \text { minggu } \\
3 \text { kali. }\end{array}$ \\
\hline 29 & $\begin{array}{l}\text { Belimbing wuluh } \\
\text { (Averrhoa bilimbi L) }\end{array}$ & Gondok & $\begin{array}{l}\text { Ambil buah belimbing wuluh secukupnya } \\
\text { rajang dan tumbuk hingga menjadi halus } \\
\text { (bubur), kemudian tempelkan pada kelenjar } \\
\text { yang membengkak selama } 30 \text { menit, } 3 \text { kali } \\
\text { sehari. }\end{array}$ \\
\hline 30 & $\begin{array}{l}\text { Pare (Momordica } \\
\text { charantia L) }\end{array}$ & Ambeyen & $\begin{array}{l}\text { Ambil akar, daun, buah dan biji pare cuci } \\
\text { dan tumbuk, peras airnya dan campurkan } \\
\text { dengan } 2 \text { sendok makan minyak kelapa, } \\
\text { kemudian basahi kapas dengan campuran } \\
\text { minyak dan akar, daun buah pare tersebut, } \\
\text { tempelkan pada amabeyen setelah } \\
\text { mengadakan rendam duduk dengan air } \\
\text { panas. }\end{array}$ \\
\hline 31 & $\begin{array}{l}\text { Nangka (Artocarpus } \\
\text { heterophyllus Lamk) }\end{array}$ & Bisul & $\begin{array}{l}\text { Ambil beberapa tetes getah nangka } \\
\text { campurkan dengan minyak kelapa } \\
\text { kemudian letakan diatas api untuk } \\
\text { memanaskan dan oleskan pada bagian } \\
\text { yang tubuh yang terkena bisul. }\end{array}$ \\
\hline
\end{tabular}

\section{Pembahasan

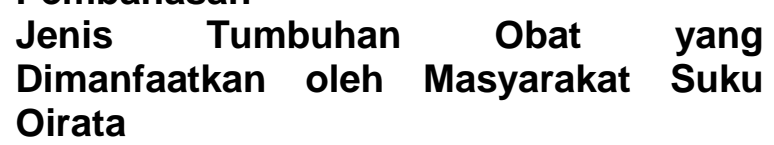

Berdasarkan hasil penelitian yang dilakukan pada Suku Oirata ditemukan 31 jenis tumbuhan obat. Jenis tumbuhan obat yang terindentifikasi ini memiliki kelompok habitus yang berbeda-beda yaitu habitus herba/terna sebanyak 5 jenis $(16,13 \%)$, habitus semak 4 jenis $(12,90 \%)$, habitus perdu 7 jenis $(22,6 \%)$, habitus pohon 12 jenis $(38,70 \%)$, dan habitus merambat 3 jenis ( $9,67 \%)$, jadi kelompok habitus tumbuhan obat yang paling banyak digunakan oleh masyrakat Suku Oirata adalah pohon karena banyak yang tumbuh di kebun mereka dan tidak mudah mati. Sedangkan menurut penelitian sebelumnya Nurhaida (2015) di Kecamatan Tanah Pinoh kelompok habitus yang paling banyak digunakan yaitu herba dikarenakan pada tingkat herba merupakan sebuah tumbuhan yang mudah dibudidayakan, cepat pertumbuhannya dan tidak memerlukan lahan yang luas.

Jenis tumbuhan obat yang yang diamanfaatkan oleh Suku Oirata Pulau Kisar Kecamatan Pulau-Pulau Terselatan Kabupaten Maluku Barat Daya untuk mengobati penyakit mereka tidak hanya menggunakan 1 jenis tumbuhan saja untuk mengobati satu penyakit tetapi 1 jenis dipergunakan untuk mengobati lebih dari satu penyakit.

\section{Jenis Penyakit yang Diobati Menggunakan Tumbuhan Obat}

Dari 31 jenis tumbuhan obat yang di temukan dapat dimanfaatakn untuk mengobati berbagai macam penyakit yaitu rambut rontok, darah tinggi, diare, demam, menyuburkan rambut, jerawat, radang tenggorokan, asma, cacar air, nyeri 
persendian, gusi bengkak, rematik, luka bakar, sakit mata, cacingan, sembelit, perut kembung, menarik darah mati pada luka, gigitan nyamuk, lidah putih pada bayi, bauh badan, batuk, keputihan, memperlancar haid, darah putih, kanker payudara, luka goresan, patah tulang, demam berdarah, penyakit kuning, bisul, gula darah (diabetes), gagal ginjal, gondok, dan ambeyen. Penyakit yang paling banyak diobati dengan menggunakan tumbuhan obat oleh masyarakat Suku Oirata Pulau Kisar Kecamatan Pulau-Pulau Terselatan Kabupaten Maluku Barat Daya yaitu penyakit darah tinggi dan diare. Menurut penelitian sebelumya Deny (2015) penyakit yang paling banyak diobati menggunakan tumbuhan obat oleh masyarakat Desa Gerantung adalah Penyakti Sakit pinggang dan Malaria. Jadi dapat diambil kesimpulan bahwa pemanfaatan tumbuhan obat oleh masyarakat dari berbagai suku maupun desa lebih banyak digunakan untuk mengobati penyakit dalam.

\section{BagianTumbuhan Obat yang Digunakan untuk Menyembuhkan Penyakit}

Tumbuhan obat yang digunakan untuk menyembuhkan penyakit bukan hanya tumbuhan yang di ambil keseluruhan bagian tumbuhannya tetapi ada juga bagian- bagian tertentu yang hanya berkhasiat sebagai obat yaitu berupa akar, batang, buah, daun, getah, rimpang. Bagian tumbuhan yang paling banyak di gunakan oleh masyrakat Suku Oirata Pulau Kisar Kecamatan Pulau-Pulau Terselatan Kabupaten Maluku Barat Daya yaitu bagian daun. Sama dengan penelitian sebelumnya Maryadi (2012) bahwa bagian yang paling banyak dimanfaatkan masyarakat adalah bagian daun, karena lebih mudah didapat ketika masyarakat membutuhkannya dan penggunaannya dapat mengobati penyakit dalam maupun penyakit luar. Hal ini dikarenakan daun umumnya bertekstur lunak karena mempunyai kandungan air yang tinggi $(70-80 \%)$ selain itu, daun merupakan tempat akumulasi fotosintesis yang diduga mengandung unsur-unsur (zat organik) yang memiliki sifat menyembuhkan penyakit. Zat yang banyak terdapat pada daun adalah minyak atsiri, fenol, senyawa kalium, alkaloid, terpenoid dan klorofil. Alkaloid merupakan golongan zat tumbuhan sekunder yang terbesar sedangkan Terpenoid dapat berperan sebagai antibakteri. Antibakteri adalah bahan alam bukan hasil sintesik bahan kimia sehingga relatif aman tanpa efek samping.

Menurut pendapat masyarakat Suku Oirata Pulau Kisar Kecamatan Pulau- Pulau Terselatan Kabupaten Maluku Barat Daya bahwa menggunakan tumbuhan obat ini tidak memiliki efek samping karena terbuat dari bahan alami dan mereka juga mengikuti pengobatan menggunakan tumbuhan obat dari nenek moyang mereka yang telah diwariskan secara turun, bahwa dengan menggunakan tumbuhan mereka akan sembuh. Begitupun sama dengan menurut Sabri ( 2011) bahwa efek samping pada ramuan tradisional sangat kecil, karena bahan bakunya sangat alami. Selain itu keterbatasan ekonomi sarana dan prasarana kesehatan menyebabkan pengobatan tradisonal menjadi pilihan pertama masyarakat untuk mengobati suatu penyakit. Pengobatan tradisional juga dapat menjadi alternatif terakhir bilamana pengobatan dengan cara modern tidak memberikan hasil.

\section{Cara Pengolahan dan Penggunaan Tumbuhan Bagi Pengobatan Penyakit.}

Dari hasil penelitian pada masyarakat Suku Oirata cara pengolahan tumbuhan obat juga bermacam-macam ada yang direbus, ditumbuk, dirajang, diperas, ditempelkan, dibalut, dipanaskan/dirau, bahkan ada yang dimakan secara langsung (dimakan mentah) untuk menelan airnya. Cara Pengolahan yang paling banyak di gunakan adalah oleh masyarakat dari Suku Oirata yaitu cara direbus karena masyarakat meyakini bahwa jika direbus dapat mengangkat zat yang terkandung dalam tumbuhan, dan mempunyai reaksi yang sangat cepat bila diminum. Berbeda halnya dengan hasil penelitian Anggraini (2014), bahwa cara penggunaan tumbuhan obat yang paling banyak ditemukan adalah cara ditumbuk dan dioles pada bagian yang sakit ini di karenakan masih banyak penyakit luar yang di obati seperti panu dan gatal-gatal.

Pengolahan tumbuhan sebagai obat tradisional yang harus diperhatikan yaitu, pencucian, pengeringan, air, cara merebus dan cara meminumnya. Dari hasil penelitian 
terlihat jelas bahwa cara pengolahan tanaman obat ada yang hanya dicampur dengan air. Hal ini didukung dengan pendapat Supriadi (2001), bahwa penggunaan jenis tanaman obat ada yang bersifat "Tunggal" berarti jenis tanaman itu digunakan tanpa campuran jenis tanaman atau bahan baku lain dan hanya dicampur dengan air. Sedangkan yang bersifat "Campuran" berarti jenis tanaman obat tersebut diolah atau digunakan dalam bentuk ramuan atau campuran dengan jenis tanaman atau bahan lain. Dari manfaat dan cara pengolahan tanaman obat di peroleh ada perbedaan manfaat dan cara pengolahan obat dari buku dengan manfaat dan cara pengolahan obat dari masyarakat..

Sedangkan untuk cara penggunaanya bagi masyarakat Suku Oirata yaitu bersifat tunggal karena mereka tidak menggunakan tumbuhan yang dicampur dengan tumbuhan atau bahan baku lain hanya dicampur dengan air.

\section{KESIMPULAN}

1. Jenis tanaman obat yang dimanfaatkan sebagai tanaman obat tradisional yaitu Jarak Pagar (Jatropa curcas L.), Canar (Smilax leucophylla), Jambu monyet (Anacardium occidentale L.), Srikaya (Annona squamosa L.), Pepaya (Carica papaya L.), Tapak Dara (Catha ranthusroseus), Alang-alang (Imperata cylindrical), Kelor (Moringa oleifera Lam), Lidah Buaya (Aloe vera L.), Jambu Biji (Psidium guajava L.), Mengkudu (Morinda citrifolia L.), Sirsak (Annona muricata L.), Asam Jawa (Tamarindus indica L.), Jeruk Nipis (Citrus $x$ aurantiifolia), Kemangi (Ocimum citriodorum), Tembelekan (Lantana camara L.), Sirih (Piper betle), Turi (Sesbania grandiflora), Jarak merah (Jatropha gossypifolia L.), Kirinyu (Chromolaena odorata L.), Sirih hutan (Piper caducibrateum C.DC), Kamboja putih (Plumeria alba), Sukun (Artocarpus altilis), Cabai (Capsicum annun L.), Kecubung (Datura metel L.), Suruhan (Peperomia pellucida), Pisang raja (Musa $X$ paradisiaca AAB), Daun afrika (Vernonia amygdalina Del), Belimbing wuluh (Averrhoa bilimbi L),
Pare (Momordica charantia L), Nangka (Artocarpus heterophyllus Lamk).

2. Jenis penyakit yang diobati menggunakan tumbuhan obat adalah rambut rontok, darah tinggi, diare, demam, menyuburkan rambut, jerawat, radang tenggorokan, asma, cacar air, nyeri persendian, gusi bengkak, rematik, luka bakar, sakit mata, cacingan, sembelit, perut kembung, menarik darah mati pada luka, gigitan nyamuk, lidah putih pada bayi, bauh badan, batuk, keputihan, memperlancar haid, darah putih, kanker payudara, luka goresan, patah tulang, demam berdarah, penyakit kuning, bisul, gula darah (diabetes), gagal ginjal, gondok, dan ambeyen.

3. Bagian tanaman yang digunakan untuk pengobatan yaitu akar, batang, kulit batang, getah, daun, buah, dan biji

4. Cara pengolahan menggunakan cara direbus, ditumbuk, diperas, digosok, ditempelkan, digiling, dibalut dan langsung di makan.

\section{DAFTAR PUSTAKA}

Adfa, M. 2005. Study Senyawa Flavonoid dan Uji Brine Shrimp Beberapa Tumbuhan Obat Tradisional Suku Serawai di Provinsi Bengkulu.

Anggraini, 2014.Pemanfaatan Tumbuhan Obat Oleh Masyarakat di Sekitar Kasawasan Hutan Adat Gunung Semaung Kecamatan Tayn Hulu Kabupaten Sanggau. Skripsi Fakultas Kehutanan Universitas Tanjungpura Pontianak.

Darsini, N.N. 2013. Analisis Keanekaragaman Jenis Tumbuhan Obat Tradisional Berkhasiat untuk Pengobatan Penyakit Saluran Kencing di Kecamatan Kintamani Kabupten Bangli Provinsi Bali.

Deny, G. 2015. Studi Tumbuhan Obat Pada Etnis Dayak di Desa Gerantung Kecamatan Monterado Kabupaten Bengkayang. Skripsi Fakultas Kehutanan Universitas Tanjungpura Pontianak.

Ngarbingan, M.J. 2009.Studi Pemanfaatan Tumbuhan Obat Tradisional Oleh Masyarakat Dusun Toisapu Desa Hutumuri Kecamatan Leitimur Selatan 
Biopendix, Volume 5, Nomor 1, Oktober 2018, hlm. 53-64

Kota Ambon.Ambon:Fakultas
Matemetika dan Ilmu Pengetahuan
Alam. Universitas Pattimura.

Nurhaida . 2015. Studi Etnobotani Tumbuhan Obat di Dusun Kelampuk Kecamatan Tanah Pinoh Barat Kabupaten Melawi. Skripsi Fakultas Kehutanan Universitas Tanjungpura Pontianak.

Masyhud. 2010. Lokakarya Nasional Tumbuhan Obat Indonesia. http://www.dephud.go.id. Diaskes 4 juni 2018.

Maryadi. 2012. Studi Etnobotani Tumbuhan Obat di Desa Seriang Kecamatan Bedau Kabupaten Kapuas Hulu. Skripsi Fakultas Kehutanan Tanjungpura Pontianak.

Putra, dkk. 2012. Studi Etnobotani Suku Serawai di Kelurahan Sukarmi Kecamatan Selebar Kota Bengkulu. Jurnal Penelitian dan Pengelolaan Sumberdaya Alam dan Lingkungan. 1 (3):217-224.

Sabri, M. 2001. Etnobotani Tumbuhan Obat Dalam Kawasan Hutan Wisata Baning Kabupaten Sintang. Skripsi Fakultas Kehutanan Tanjungpura Pontianak.

Supriadi. 2001. Tumbuhan Obat Indonesia: Penggunaan dan Khasiatnya. Pustaka Populer Obor. Jakarta. 